\title{
EL TRIBUNAL DE JUSTICIA AL RESCATE DE LOS DERECHOS EN EL CONTEXTO DE LAS MEDIDAS DE ESTABILIDAD DERIVADAS DE LA CRISIS ECONÓMICA: PRINGLE V LEDRA ADVERTISING
}

\author{
FEDERICO DE MONTALVO JÄÄSKELÄINEN \\ Profesor Propio Adjunto Derecho constitucional \\ ICADE. UPComillas
}

I consider, then, the power to annul a law of the United States, assumed by one State, incompatible with the existence of the Union, contradicted expressly by the letter of the Constitution, unauthorized by its spirit, inconsistent with every principle on which It was founded, and destructive of the great object for which it was formed.

Andrew Jackson

\section{SUMARIO}

I. Introducción; II. La Unión ante la crisis económica: la ampliación de competencias económicas a través del Mecanismo Europeo de Estabilidad; III. El Tribunal de Justicia al rescate de los rescates: el caso Pringle; IV. El Tribunal de Justicia al rescate de los derechos: el caso Ledra Advertising.

\section{INTRODUCCIÓN}

El Tribunal de Justicia ha ostentado desde el origen de la Unión Europea un papel protagonista en el proceso de integración europea a través de su función de garantía de respeto del Derecho en la interpretación y aplicación de los Tratados. Dicha posición protagonista del Tribunal que, en muchas ocasiones acudía a argumentos más político-constitucionales que de mera y estricta técnica jurídica, responde al objetivo de garantizar la efectividad del Derecho europeo. El Tribunal ha pretendido a través de su relativo activismo judicial mostrar con claridad que el Derecho europeo tenía carácter vinculante y era útil para resolver jurídicamente conflictos sociales en el espacio europeo. La determinación de la eficacia 
directa del Derecho europeo, la idea de que los ciudadanos podían fundar pretensiones subjetivas en el Derecho europeo, la aparición del principio de primacía, la obligación del juez de aplicar disposiciones europeas frente a las nacionales, la garantía de los derechos fundamentales como principios generales del Derecho, la posterior extensión de los efectos directos de fuentes como la directiva, el principio de responsabilidad del Estado por incumplimiento, etc., no son sino elementos jurídicos que garantizan, no ya la eficacia de las disposiciones europeas en el ordenamiento de los Estados miembros, sino la propia existencia del ordenamiento europeo. Mediante su jurisprudencia creativa y la producción de principios generales autónomos, el Tribunal de Justicia trató de conceder validez al Derecho europeo como nuevo y auténtico ordenamiento jurídico frente a los ordenamientos estatales ${ }^{1}$.

Tal posición, además, se muestra comprensible si atendemos a la propia condición de organización supranacional de la Unión lo que podría haberle otorgado un carácter más de soft law a las normas de su ordenamiento jurídico, lo que desde un principio pretendió evitar el Tribunal. Este extremo es solventado por el Tribunal como nos recuerda Aguilar Calahorro cuando señala que el Tribunal parecía dejar constancia con su jurisprudencia de que un ordenamiento sólo es válido si es realmente efectivo, esto es, si los sujetos a los que va destinado lo consideran un conjunto de reglas jurídicas vinculantes, útil para la resolución de conflictos sociales y, en consecuencia, se aferran a sus disposiciones para defender y fundar pretensiones subjetivas ante el juez. Por ello se esmeró en la producción de todo un conjunto de principios de aplicación de las disposiciones europeas que permitieran hacer visible a los ciudadanos la utilidad del Derecho europeo ${ }^{2}$.

En todo caso, dicha posición que desde el inicio cobra el Tribunal de Justicia encaja plenamente con la que adoptaron tras la Segunda Guerra Mundial muchos de los Tribunales Constitucionales de los principales Estados que poco después integrarían e impulsarían la creación de las Comunidades Europeas (véase, en particular, la posición que en el sistema constitucional alemán o italiano han tenido y tienen sus Tribunales Constitucionales) ${ }^{3}$.

1 Aguilar Calahorro, A., «La posición del Tribunal de Justicia de la Unión Europea frente a las medidas de la crisis económica», RDCE, n. ${ }^{\circ} 24,2015$, p. 1.

2 Ibidem, p. 4.

3 Vid. Ahumada Ruíz, M., La jurisdicción constitucional en Europa, Thomson-Civitas, Cizur Menor, 2005, pp. 39 y ss. Vid., también, la monografía de M. González Pascual sobre el papel que ha ostentado el TC Federal de Alemania en la división de poderes en dicho Estado, González Pascual, M., El Tribunal Constitucional alemán en la construcción del espacio europeo de los derechos, Thomson Reuters, Cizur Menor, 2010. Requejo Pagés considera que tal fortalecimiento de la función revisora de la Ley que altera la tradición europea se ha producido fundamentalmente en los países del Continente que no habían disfrutado hasta entonces (1. ${ }^{\mathrm{a}}$ mitad del siglo xx) de una tradición democrática en el marco del Estado de Derecho. De este modo, y coincidiendo con el autor, los que sí habían gozado de dicha tradición no verán la necesidad de recurrir al poder contramayoritario o, al menos, lo harán con menos fuerza rompedora (véase, Reino Unido o Países Bajos). Vid. REQUEJo PAGÉs, J.L., «El final de un privilegio. Apuntes sobre un modelo europeo de Justicia Constitucional», VVAA, La Constitución política de España. Estudios en homenaje a Manuel Aragón Reyes, CEPC, Madrid, 2016, pp. 344 y 345. 
En relación a esta convivencia entre jurisdicción constitucional y jurisdicción comunitaria, se ha apuntado con acierto que precisamente el desarrollo de ésta última puede suponer que las primeras empiecen a ser vistas como instituciones disfuncionales como consecuencia de la coexistencia de un doble modelo de revisión, el concentrado respecto de las normas constitucionales y el difuso respecto de las normas comunitarias. Sin embargo, y esta es la auténtica paradoja, la consagración del modelo revisor comunitario también puede provocar que los Tribunales Constitucionales nacionales encuentren una nueva razón para su existencia, ya que la previsión de la identidad nacional como un límite al ejercicio de los poderes de la Unión (art. 4.2 TUE) requerirá el concurso de interlocutores nacionales capaces de colaborar con el Tribunal de Justicia en la delimitación de un concepto que exige en su definición el consenso de los Estados ${ }^{4}$.

La posición de fuerza del Tribunal de Justicia ha encontrado su hito en diferentes ámbitos en los que su doctrina ha ido más allá de las intenciones de la Comisión, Consejo y Parlamento en la creación de un verdadero espacio común jurídicos.

Como vamos a ver a continuación, dicho papel protagonista en garantía del Derecho de la Unión y también de la Carta ha sido adoptado también en su control de las medidas de rescate financiero de los Estados miembros de la zona Euro que han quedado sujetos a un Memorándum dentro del Mecanismo Europeo de Estabilidad, sin perjuicio de que inicialmente el propio Tribunal se hubiera mostrado excesivamente cauto a la hora de someter éstas al escrutinio de aquéllas normas y, principalmente, de la Carta.

\section{LA UNIÓN ANTE LA CRISIS ECONÓMICA: LA AMPLIACIÓN DE COMPETENCIAS ECONÓMICAS A TRAVÉS DEL MECANISMO EUROPEO DE ESTABILIDAD}

La crisis económica de finales de la primera década del siglo XXI planteó un importante reto para la Unión como era el de cohonestar sus facultades de intervención sobre las economías de los Estados miembros, muy limitadas por obra de los Tratados, con la necesidad de mantener la estabilidad económica, al menos,

4 Requejo Pagés, J.L., «El final de un privilegio. Apuntes sobre un modelo europeo de Justicia Constitucional», op. cit., pp. 345 y 346.

5 Véase, entre otras, la posición que el Tribunal de Justicia adoptó desde hace ya años en la construcción de un espacio común de atención sanitaria en la Unión Europea. Así, frente a una materia en la que las competencias de la Unión quedaban relegadas, según previsión de los Tratados, a una mera facultad de cooperación y coordinación, se crea un verdadero espacio de asistencia transfronteriza al interpretar el Tribunal que la libre circulación de pacientes deriva de los propios principios fundadores de la Unión. Vid. De MonTALVO JAASKELAinen, F., «A european common framework for health: real possibility of an improbable myth? Lessons for the future healthcare system in the United States», De Paul Journal of Health Care Law, vol. 14, n. ${ }^{\circ}$ 2, 2012, pp. 189 a 233. 
de la zona Euro ${ }^{6}$. Se ha afirmado de manera muy ilustrativa que la Unión y, en particular, la eurozona, llegó a la crisis económica con una situación en la que, pese a compartir una moneda, carecía de la suficiente integración de sus mercados financieros y de su banca. Además, carecía de un presupuesto «federal» que le permitiera afrontar las recesiones severas que iban a padecerse, y también de competencias en materia fiscal, de tal manera que no era posible generar nuevos recursos para que los Estados pudieran solventar sus problemas de financiación ${ }^{7}$.

Los Tratados se mostraban excesivamente parcos en el ámbito económico y financiero de manera que no daban fundamento jurídico suficiente a la adopción de políticas de intervención económica y de ayuda, impidiendo prima facie una política económica común que permitiera solventar las turbulencias económicas y los problemas derivados del excesivo endeudamiento de los Estados miembros en una contexto en el que los mercados ya no ofrecían un acceso fácil a la financiación. Más aún, de los Tratados y especialmente del TFUE se deducía, aunque con una excepción que veremos de inmediato, que tales medidas no sólo carecían de apoyo normativo, sino que incluso podían ser consideradas contrarias al Derecho de la Unión. Ello se deducía de los dispuesto por el artículo 125 TFUE que establecía la prohibición de la corresponsabilidad financiera, lo que se completaba con la prohibición de acceso privilegiado a la financiación mediante entidades de crédito o el BCE que se recogía en el artículo 123 TFUE (prohibición de autorización de descubiertos o la concesión de cualquier otro tipo de créditos por el BCE y por los bancos centrales de los Estados miembros en favor de instituciones, órganos u organismos de la Unión, Gobiernos centrales, autoridades regionales o locales u otras autoridades públicas, organismos de Derecho público o empresas públicas de los Estados miembros, así como la adquisición directa a los mismos de instrumentos de deuda por el Banco Central Europeo o los bancos centrales nacionales).

Frente a ello, el artículo 122 TFUE admitía la posibilidad extraordinaria de financiación con cargo al presupuesto de la Unión. Así, este último precepto permitía al Consejo, a propuesta de la Comisión, decidir, con un espíritu de solidaridad entre Estados miembros, medidas adecuadas a la situación económica, en particular si surgieren dificultades graves en el suministro de determinados productos, especialmente en el ámbito de la energía (apartado 1). Junto a ésta adopción de medidas excepcionales se permitía también la concesión de ayuda financiera de la Unión a un Estado miembro en caso de dificultades o en caso de serio riesgo de dificultades graves en un Estado miembro, ocasionadas por catástrofes naturales o acontecimientos excepcionales que dicho Estado no pudiere

6 Como nos recuerda Hinarejos, el art. 2.3 TFUE se limita a otorgar un mero papel coordinador a la UE, papel que además no queda claramente precisado. Vid. Hinarejos, A., The Euro Area crisis in constitutional perspective, Oxford University Press, Oxford, 2015, p. 29.

7 Estella, A., «¿Hacia una Unión Bancaria Europea? El Mecanismo Único de Supervisión Bancaria (MUS)», RGDE, n. ${ }^{\circ} 33,2014$, p. 3. 
controlar (apartado 2). En todo caso, el tenor del citado artículo 122 parecía referirse a situaciones extraordinarias y muy puntuales.

Como acertadamente señala Frosina, los Tratados, tal y como fueron modificados por el Tratado de Lisboa, no preveían instrumentos de apoyo a Estados miembros con crisis de liquidez, sino que por el contrario el TFUE imponía una prohibición de rescate conocida como bailout (art. 125), al tiempo que imponía a los Estados evitar un déficit público excesivo (art. 126). La única excepción a este esquema se dispone en el artículo 122 TFUE que admite la posibilidad de una asistencia financiera por parte de la Unión Europea a los Estados en situación de crisis, pero sólo en determinadas ocasiones extraordinarias aparejadas a situaciones de grave dificultad económica provocada por calamidades naturales o circunstancias excepcionales que escapen al control de los Estados ${ }^{8}$. La falta de mecanismos de ayuda financiera a los Estados ha constituido uno de los principales problemas con el que se encontraron las Instituciones Europeas en el momento de afrontar situaciones urgentes derivadas de la crisis?.

Estos mecanismos de Derecho, se mostraban, por tanto, ineficaces o, al menos, insuficientes, para hacer frente a la crisis, lo que provocó diferentes tipos de decisiones. En primer lugar, se promovió fortalecer la posición institucional del $\mathrm{BCE}^{10}$. Al mismo tiempo se adoptaron dos tipos de medidas ${ }^{11}$ : por un lado, utilizar en todo su potencial los mecanismos previstos legalmente, sobre todo, lo

8 Este artículo puede ser considerado como una de las mayores expresiones del principio de solidaridad entre los Estados miembros que fundamenta a la propia creación de la Unión y a su Derecho. Junto a este precepto puede citarse también el art. 143.2 TFEU, el cual hace referencia a dicha solidaridad respecto de Estados miembros fuera de la Zona euro. Vid. Borger, V., «How the Debt Crisis Exposes the Development of Solidarity in the Euro", European Constitutional Law Review, n. ${ }^{\circ}$ 9, 2013, p. 14 . Ya el Tribunal de Justicia se refirió muy tempranamente al principio de solidaridad en 1969, en el caso Comisión contra Francia, 10 de diciembre de 1969 , caso n. ${ }^{\circ} 11 / 69$, ap. 16.

9 Frosina, L., «Reformas en la gobernanza e incertidumbres en la culminación de la Unión económica y monetaria», Revista de Derecho Constitucional Europeo, n. ${ }^{\circ} 25,2016$, p. 2.

10 El BCE ha visto reforzada su función supervisora recientemente; en concreto, en noviembre de 2014 el BCE ha asumido nuevas competencias y responsabilidades como supervisor bancario para más de 6000 bancos de la zona del euro. La cuestión de hasta qué punto el Banco Central Europeo debería dedicarse a la supervisión bancaria ha sido una de las cuestiones más controvertidas para el Comité Delors a finales de los años ochenta y en la propia redacción del Tratado de Maastricht. Los gobiernos nacionales habitualmente han presionado para mantener la supervisión como una prerrogativa nacional. El marco institucional resultante creado por el Tratado de Maastricht limitó gravemente la capacidad de las instituciones de la UE y del propio BCE (es decir, el BCE) de proporcionar una supervisión preventiva. Vid. AleXAnder, K., «The ECB and Banking Supervision: Building Effective Prudential Supervision?», Yearbook of European Law, Vol. 33, n. ${ }^{\circ} 1$, 2014, pp. 417 y 419.

11 Elías Méndez, C., «El papel de las Instituciones europeas ante la crisis económica: Banco Central Europeo, Consejo Europeo, Consejo de la Unión Europea, Comisión Europea y Parlamento Europeo», BALAguer Callejón, F., Azpitarte Sánchez, M., Guillén lópez, E. y Sánchez Barrilao, F. (Eds.), El impacto de la crisis económica en las Instituciones de la UE y los Estados miembros, Thomson Reuters-Aranzadi, Cizur Menor, 2015, p. 36. Frosina considera que las medidas y reformas adoptadas con el fin de salvar a la Unión y los Estados miembros de la inestabilidad económica se han caracterizado, a grandes rasgos, por su desorganización y fragmentariedad, lo que revela: 1) la ausencia de un diseño unitario; 2) un fuerte experimentalismo; 3) una amplia flexibilidad en sus contenidos; 4) la diversa naturaleza, de necesidad o estructural, y eficacia, 
establecido, aún de manera excepcional, en el apartado 2 del artículo 122 TFUE; $y$, por el otro, ampliar dichas facultades a través de la creación de nuevas funciones $^{12}$ y mecanismos. Entre estos últimos, hay que destacar singularmente el Mecanismo Europeo de Estabilidad para compensar las deficiencias de financiación de los Estados cuando acudían a los mercados ${ }^{13}$. El Mecanismo se crea a través de la reforma del Tratado de Lisboa mediante la Decisión 2011/199/UE de reforma del art. 136 TFUE, mediante el procedimiento simplificado, incorporando un apartado 3 del siguiente tenor literal: «Los Estados miembros cuya moneda es el euro podrán establecer un mecanismo de estabilidad que se activará cuando sea indispensable para salvaguardar la estabilidad de la zona del euro en su conjunto. La concesión de toda ayuda financiera necesaria con arreglo al mecanismo se supeditará a condiciones estrictas». El Mecanismo será considerado el instrumento necesario para hacer frente a casos de riesgo para la estabilidad financiera de la zona del euro en su conjunto como los experimentados en 2010, contribuyendo a preservar la estabilidad económica y financiera de la propia Unión. Así, en su sesión de los días 16 y 17 de diciembre de 2010, el Consejo Europeo convino en que, como este mecanismo tendrá por objeto salvaguardar la estabilidad financiera de la zona del euro en su conjunto, la medida extraordinaria de financiación con cargo al presupuesto de la UE prevista en el artículo 122, apartado 2 TFUE ya no será necesario para tal fin, conviniendo los Jefes de Estado y de Gobierno en que no se utilice con este propósito.

Previamente a dicha reunión del Consejo, la Unión ya había hecho suya la necesidad de crear un mecanismo que permitiera solventar la situación existente. Y así, mediante el Reglamento 407/2010 de 11 de mayo de 2010 ${ }^{14}$, el Consejo estableció el Mecanismo Europeo de Estabilización Financiera (MEEF) con el objetivo de precisar las condiciones y procedimientos en los que se podría

preventiva o correctiva, de sus procedimientos. Frosina, L., «Reformas en la gobernanza e incertidumbres en la culminación de la Unión económica y monetaria», cit., p. 3.

12 Entre la ampliación de funciones destaca la atribución de la competencia de supervisión bancaria al BCE, lo que va más allá de su función inicial de política monetaria. La política monetaria suele implicar el uso de unos pocos instrumentos macro — que controlan las tasas de interés y la cantidad de dinero- para lograr la estabilidad de precios, un objetivo mensurable definido a menudo como mantener la inflación dentro de un rango o por debajo de un objetivo. Por su lado, la supervisión bancaria tiene un mayor número de objetivos, a menudo contradictorios: estabilidad financiera, protección de los inversores y los depositantes, protección de los consumidores y delincuencia financiera. Por otra parte, es mucho más difícil medir si se han alcanzado estos objetivos y cuáles son los compromisos económicos para lograrlos. Además, los supervisores bancarios tienen el poder de restringir y reestructurar los derechos de propiedad y contractuales — pertenecientes a firmas individuales, depositantes, accionistas y acreedores - y, al hacerlo, utilizar un número mucho mayor de instrumentos regulatorios de los que está disponible en la política monetaria. Vid. AleXander, K., «The ECB and Banking Supervision: Building Effective Prudential Supervision?», cit., p. 429. Este nuevo papel ha de tener, además, mayor impacto en los derechos y en la propia Carta, por las funciones que implica y la mayor posibilidad de incidir sobre el derecho de propiedad y otros.

13 Aguilar Calahorro, A., «La posición del Tribunal de Justicia de la Unión Europea frente ...», cit., pp. 16 y 17 .

14 DO L 118 de 12 de mayo de 2010, p. 1. 
conceder ayuda financiera a un Estado que reuniese los requisitos previstos en el art. 122.2 TFUE que prevé que «en caso de dificultades o en caso de serio riesgo de dificultades graves en un Estado miembro, ocasionadas por catástrofes naturales o acontecimientos excepcionales que dicho Estado no pudiere controlar, el Consejo, a propuesta de la Comisión, podrá acordar, en determinadas condiciones, una ayuda financiera de la Unión al Estado miembro en cuestión». Y posteriormente, el Consejo Europeo en su reunión de 28 y 29 de octubre de 2010 decidió que era necesario, para garantizar la estabilidad financiera de la zona euro, que se creara un mecanismo permanente para hacer frente a las posibles crisis venideras ${ }^{15}$. Las características generales del nuevo instrumento fueron definidas en su Declaración del 28 de noviembre de 2010, y confirmadas por el Consejo Europeo en la citada reunión de 16 y 17 de diciembre de $2010^{16}$.

El Mecanismo adopta la forma de organismo intergubernamental de Derecho internacional público y tiene por finalidad movilizar fondos y proporcionar apoyo a la estabilidad ${ }^{17}$, bajo una estricta condicionalidad, adaptada al instrumento de asistencia financiera elegido, a los miembros del mismo (Estados miembros zona euro) que experimenten o corran el riesgo de experimentar graves problemas de financiación, cuando ello sea indispensable para salvaguardar la estabilidad financiera de la zona del euro en su conjunto y de sus Estados miembros. Con este fin, el Mecanismo estará facultado para obtener fondos a través de la emisión de instrumentos financieros o mediante la celebración de acuerdos o convenios de índole financiera o de otro tipo con sus propios

15 AsENSI, A., «Las ayudas estatales al sector financiero y su supervisión en el contexto de la Unión Bancaria Europea», RDCE, n. ${ }^{\circ} 23$, enero-junio 2015, p. 15.

16 La necesidad de un mecanismo más estable vino motivado por el agravamiento de la crisis y por la solicitud de ayuda de España. Vid. Frosina, L., «Reformas en la gobernanza e incertidumbres en la culminación de la Unión económica y monetaria», cit., p. 5.

17 La naturaleza intergubernamental del Mecanismo se observa en las mayorías necesarias para la adopción de las decisiones. Las decisiones relativas a cuatro cuestiones nucleares se adoptarán por mutuo acuerdo: la concesión de asistencia financiera, las condiciones en las que ésta será concedida, la capacidad crediticia del Mecanismo y los posibles cambios en los posibles instrumentos de asistencia financiera que puede adoptar el Mecanismo. En el resto de los supuestos, las decisiones del Consejo de Gobernadores se adoptarán por mayoría cualificada, que supone el $80 \%$ de los votos ponderados, que será determinada conforme a la parte de capital del Mecanismo suscrita por cada uno de los Estados. Vid. Urbaneja Cillán, J., «El Mecanismo Europeo de Estabilidad. Análisis a través de la Jurisprudencia comunitaria en el asunto Pringle», Anuario de la Facultad de Derecho, vol. XXX, 2012-2013, p. 138. Cuando se trate de una situación en la que la Comisión y el BCE concluyan que la no adopción de forma urgente de una decisión para conceder o aplicar una asistencia financiera amenazaría la sostenibilidad económica y financiera de la zona del euro, la adopción de una decisión de común acuerdo por el Consejo de Gobernadores y el Consejo de Administración en el marco de dicho procedimiento de urgencia requerirá una mayoría cualificada del $85 \%$ de los votos expresados. El porcentaje exigido ha sido criticado por algunos autores, sobre todo, procedentes de países no mediterráneos. Así, Ginter señala que «This way of calculating the qualified majority, which is unprecedented in EU law, gives Italy, France and Germany, who all contribute more than $15 \%$ of the capital, an absolute veto power and, in turn, reduces the significance of the votes of majority of other member states». Vid. GINTER, C., «Constitutionality of the European Stability Mechanism in Estonia: Applying Proportionality to Sovereignty», European Constitutional Law Review, n. ${ }^{\circ}$ 9, 2013, p. 338. 
miembros, entidades financieras u otros terceros. El apoyo a la estabilidad financiera de un Estado miembro del Mecanismo queda sujeto a estricta condicionalidad, adaptada al instrumento de asistencia financiera elegido. Dicha condicionalidad podrá adoptar diversas formas, desde un programa de ajuste macroeconómico hasta una obligación de cumplimiento continuo de las condiciones de elegibilidad preestablecidas.

El nuevo artículo 136 TFUE, reformado al amparo de la creación del Mecanismo y tras algunas reticencias presentadas por el Reino Unido ${ }^{18}$, permite a los Estados crear un mecanismo alternativo de financiación para salvaguardar la Zona Euro en su conjunto y siempre bajo estrictas condiciones macroeconómicas. Estas estrictas condiciones macroeconómicas suponen que cuando un Estado requiera de un sistema de financiación alternativo al de los mercados privados de deuda, éste tendrá que firmar un compromiso internacional denominado memorándum de entendimiento en el que se establecerán estrictos requisitos de política macroeconómica que condicionarán en todo momento la ayuda financiera. Estas condiciones del Mecanismo tienen la misma finalidad que las prohibiciones de financiación privilegiada y de corresponsabilidad financiera: fomentar una política presupuestaria sana y responsable por parte de los Estados. Por tanto, la ayuda financiera, al quedar condicionada, no permite a los Estados relajar su política presupuestaria sana y es compatible con las prohibiciones del Tratado, concretamente, con las establecidas en los artículos 123 y 125 TFUE. Pese a ello, puede también afirmarse que esta reforma del artículo 136 TFUE ha supuesto realmente el fin de la genérica y estricta prohibición de bail-out sobre la que se había parcialmente articulado la disciplina fiscal de los Estados de la zona euro ${ }^{19}$.

El procedimiento de concesión del apoyo financiero se inicia mediante la solicitud del Estado miembro al presidente del Consejo de Gobernadores, principal órgano de control y supervisión del Mecanismo y que está integrado por los ministros de Economía y Finanzas de los Estados miembros de la eurozona, quienes poseen derecho al voto. Tras la recepción de dicha solicitud, el presidente del Consejo de Gobernadores encomendará a la Comisión Europea, en coordinación con el BCE, evaluar la existencia de un riesgo para la estabilidad financiera de la

18 Debe recordarse que la reforma del citado artículo 136 permitió a los Estados de la Zona euro firmar el 2 de febrero de 2012 el Tratado sobre el Mecanismo Europeo de Estabilidad. Para la entrada en vigor del Tratado, se debió esperar a la ratificación de Alemania que tuvo a su vez que esperar el visto bueno del Tribunal Constitucional federal alemán. Éste último se pronunció el 12 de septiembre de 2012 a favor de la legitimidad constitucional de la ley interna de ratificación del Tratado, aunque exigió el respeto riguroso de condiciones destinadas a salvaguardar la centralidad de la democracia parlamentaria en el ordenamiento constitucional alemán. Vid. Frosina, L., «Reformas en la gobernanza e incertidumbres en la culminación de la Unión económica y monetaria», cit., p. 5. Sobre la decisión del Tribunal Constitucional Federal alemán, puede verse Daranás Peláez, M., «Comentario a la Sentencia del Tribunal Constitucional Federal alemán sobre el Mecanismo Europeo de Estabilidad (MEDE)», Revista Parlamentaria de la Asamblea de Madrid, n. ${ }^{\circ} 27$, diciembre 2012, pp. 279 a 381.

19 Medina Guerrero, M., «La constitucionalización de la regla del equilibrio presupuestario: integración europea, centralización nacional», Revista de Estudios Políticos, n. ${ }^{\circ}$ 165, julio-septiembre 2014, p. 191. 
zona del euro en su conjunto o de sus Estados miembros, evaluar la sostenibilidad de la deuda pública y evaluar las necesidades reales o potenciales de financiación del miembro del MEDE en cuestión. Si se adopta una decisión de apoyo, el Consejo de Gobernadores encomendará a la Comisión Europea negociar con el miembro del Mecanismo en cuestión un Memorándum de Entendimiento en el que se defina con precisión la condicionalidad asociada al instrumento de asistencia financiera ${ }^{20}$. La actuación del Mecanismo no tiene, sin embargo, que ser necesariamente una actuación de ultima ratio, ya que se admite la posibilidad de acordar un programa de asistencia con carácter preventivo ${ }^{21}$.

Desde el punto de vista de los principios que inspiran a la Unión, el Mecanismo se fundamenta en el principio de solidaridad. Como señalara el Abogado General Kokott en el caso Pringle del que vamos a dar inmediatamente cuenta, prohibir a los Estados conceder asistencia a sus socios europeos va en contra del principio de solidaridad que fundamenta a la Unión y, por tanto, en contra de la finalidad y objetivo de la Unión, por lo que aquél ha de considerarse conforme al Derecho de la Unión ${ }^{22}$.

En la aprobación del Mecanismo se estableció que el TJUE será el competente para pronunciarse sobre cualquier controversia entre las Partes Contratantes o entre éstas y el Mecanismo relativa a la interpretación y aplicación del presente Tratado, de conformidad con el artículo 273 TFUE. Y este mismo papel protagonista se le ha otorgado también poco después y en el mismo ámbito de las medidas a adoptar frente a la crisis por el Tratado de Estabilidad, Coordinación y Gobernanza en la Unión Económica y Monetaria, firmado en Bruselas el 2 de marzo de 2012, que de conformidad con su artículo 3.2 imponía a los Estados signatarios la obligación incorporar la regla del equilibrio presupuestario a sus respectivos ordenamientos jurídicos, mediante disposiciones que tuvieran fuerza vinculante y fueran de carácter permanente, preferentemente de rango constitucional, o cuyo respeto y cumplimiento estuvieran de otro modo plenamente garantizados a lo largo de los procedimientos presupuestarios nacionales. Dicho Tratado atribuye al Tribunal de Justicia la competencia para resolver los posibles incumplimientos que le planteen la Comisión o cualquier Parte Contratante, habida cuenta de que su sentencia «será vinculante para las partes en el procedimiento, que adoptarán las medidas necesarias para dar cumplimiento a la sentencia en el plazo que decida dicho Tribunal (art. 8.1). En la hipótesis de que no se llevaran a efecto tales medidas, podría solicitarse al Tribunal de Justicia la

20 Desde su activación el MEDE ha concedido asistencia financiera para recapitalizar las instituciones bancarias españolas, también a Chipre y en su marco de aplicación se ha aprobado el tercer acuerdo de préstamo para Grecia. Vid. Frosina, L., «Reformas en la gobernanza e incertidumbres en la culminación de la Unión económica y monetaria», cit., pp. 6 y 7.

21 Urbaneja Cillán, J., «El Mecanismo Europeo de Estabilidad. Análisis a través de la Jurisprudencia comunitaria en el asunto Pringle», cit., p. 139.

22 Borger, V., «How the Debt Crisis Exposes the Development of Solidarity in the Euro», cit., p. 8. 
imposición de sanciones pecuniarias (art. 8.2). A este respecto, debe recordarse que aquellos Estados abocados a recibir el apoyo financiero europeo en el marco del Mecanismo debían previamente ratificar aquél Tratado de Estabilidad ${ }^{23}$.

\section{EL TRIBUNAL DE JUSTICIA AL RESCATE DE LOS RESCATES: EL CASO PRINGLE}

El Mecanismo en sí mismo quedó sujeto al control del Tribunal en el caso Pringle (Thomas Pringle contra Governement of Ireland, Ireland y The Attorney Gene$\mathrm{ral})^{24}$, en el que se discutió tanto sus aspectos procedimentales (aprobación a través del procedimiento simplificado) como materiales. En esta decisión el Tribunal se muestra una vez más como el verdadero protagonista de la evolución de la UE, ya que entra a valorar no sólo aspectos procedimentales sino también materiales de la decisión de reformar los Tratados para incorporar las competencias que supone el Mecanismo ${ }^{25}$.

El caso Pringle surge de la petición de decisión prejudicial formulada ante la Corte Suprema de la República de Irlanda por un parlamentario irlandés, Sr. Pringle, sobre la validez de la Decisión 2011/199/UE del Consejo Europeo, de 25 de marzo de 2011, que modifica el artículo 136 del TFUE en relación con el Mecanismo. Tal petición venía en solicitar se declarara que la mencionada modificación del artículo 136 TFUE por el artículo 1 de la Decisión 2011/199 constituía una modificación ilegal del TFUE, obligando a la República de Irlanda a asumir unas obligaciones incompatibles con los Tratados en los que se fundamenta la UE.

Resumidamente, en dicha decisión el Tribunal examinó, por un lado, si la modificación del TFUE prevista por la Decisión 2011/199 afectaba únicamente a disposiciones de la tercera parte del TFUE, lo que permitiría acudir al procedimiento simplificado y, por otro, si no aumentaba las competencias atribuidas a la Unión en los Tratados. En cuanto a la primera cuestión, el Tribunal de Justicia no entra a valorar la reforma en sí del Tratado, lo que no parece que sea congruente al tratarse de Derecho originario, sino la validez del procedimiento empleado, para lo que no puede negársele tal competencia ya que, en el caso de constatarse infracción alguna, se trataría precisamente de una vulneración del

23 Medina Guerrero, M., «La constitucionalización de la regla del equilibrio presupuestario: integración europea, centralización nacional», cit., pp. 192 y 193.

24 Sentencia del Tribunal de Justicia (Pleno) de 27 de noviembre de 2012, Asunto C-370/12.

25 El Gobierno español mantuvo en el procedimiento que, dado que la Unión no era una parte contratante del Tratado MEDE, el Tribunal de Justicia no era competente para interpretar las disposiciones de ese Tratado en un procedimiento prejudicial, lo que fue rechazado de plano por el Tribunal ya que lo que pretendía la cuestión prejudicial era la interpretación de diferentes disposiciones del Derecho de la Unión y no la interpretación de disposiciones del Tratado MEDE, siendo el Tribunal competente para facilitar al tribunal nacional todos los elementos de interpretación del Derecho de la Unión que le permitan apreciar la compatibilidad de las disposiciones del Tratado MEDE con el Derecho de la Unión. 
citado Derecho originario, ya sea de sus condiciones formales como de sus límites materiales. El Tribunal de Luxemburgo es competente para controlar si se ha respetado el procedimiento formal de la reforma ${ }^{26}$.

Pues bien, el Tribunal constata que la Decisión 2011/199 modifica una disposición de la tercera parte del Tratado, a saber, el artículo 136 TFUE, y cumple así formalmente la condición enunciada en el artículo 48 TUE, apartado 6, párrafos primero y segundo, por la que el procedimiento de revisión simplificado sólo puede afectar a disposiciones de esa tercera parte.

Sin embargo, por la Corte Suprema de la República de Irlanda se preguntaba prejudicialmente si la citada revisión del TFUE no afectaba, más allá de la tercera parte del Tratado, a disposiciones de la primera parte de éste, invadiendo la competencia de la Unión en materia de política monetaria y de coordinación de las políticas económicas de los Estados miembros. Ello, en palabras del Tribunal de Justica, exige determinar si la Decisión 2011/199, al modificar el artículo 136 TFUE, atribuye a las instituciones de la Unión una competencia en el ámbito de la política monetaria en lo que concierne a los Estados miembros cuya moneda es el euro. Si así fuera, la modificación del Tratado considerada invadiría la competencia exclusiva de la Unión prevista en el artículo 3 TFUE, apartado 1, letra c), y, dado que esa última disposición forma parte de la primera parte del TFUE, tal modificación sólo podría llevarse a cabo por el procedimiento de revisión ordinario previsto en el artículo 48 TUE, apartados 2 a 5 .

Tal objeción la salva el Tribunal de Justicia considerando que el objetivo pretendido por el Mecanismo es preservar la estabilidad de la zona del euro en su conjunto, lo que se diferencia con claridad del objetivo de mantener la estabilidad de los precios, que constituye el objetivo principal de la política monetaria de la Unión. En efecto, aun si la estabilidad de la zona del euro puede tener repercusiones en la estabilidad de la moneda utilizada en esa zona, una medida de política económica no puede equipararse a una medida de política monetaria por el solo hecho de que pueda tener efectos indirectos en la estabilidad del euro. Por otro lado, el Tribunal de Justicia considera que, en lo referente a los medios previstos para lograr el objetivo pretendido, la Decisión 2011/199 únicamente precisa que el mecanismo de estabilidad concederá toda ayuda financiera necesaria y no incluye ninguna otra indicación sobre el funcionamiento de ese mecanismo. Ahora bien, evidentemente la concesión de una ayuda financiera a un Estado miembro no forma parte de la política monetaria.

Por todo ello, el Tribunal de Justicia concluye que el establecimiento del referido mecanismo no está incluido en el ámbito de la política económica, y ello, pese a que el BCE emitiera en el proceso de aprobación del Mecanismo dictamen, ya que el Consejo Europeo consultó al BCE por su propia iniciativa y no a causa de

26 Aguilar Calahorro, A., «La posición del Tribunal de Justicia de la Unión Europea frente ...», cit., p. 347. 
una obligación que le incumbiera en virtud de esa disposición, conforme lo dispuesto en el artículo 48 TUE, apartado 6, párrafo segundo, que dispone que «el Consejo Europeo se pronunciará por unanimidad previa consulta ... al BCE en el caso de modificaciones institucionales en el ámbito monetario», no pudiendo la mera consulta al BCE sobre el proyecto afectar a la naturaleza del mecanismo de estabilidad previsto. Para el Tribunal se trata de un mero mecanismo de financiación, no de coordinación de las políticas económicas de los Estados miembros ${ }^{27}$.

Además, el TJUE consideró también que la decisión, más allá del procedimiento empleado, no afecta materialmente al marco de competencias de la UE en materia de coordinación de las políticas económicas de los Estados miembros, tanto por la naturaleza permanente del mecanismo previsto como el hecho de que sus actividades pretenden preservar la estabilidad financiera en la zona del euro en conjunto. Ello le permite al Tribunal afirmar que una medida similar no podía haber sido adoptada al amparo del artículo 122 TFUE, apartado 2, que se refiere a ayudas financieras puntuales a un Estado miembro en caso de dificultades o en caso de serio riesgo de dificultades graves ocasionadas por catástrofes naturales o acontecimientos excepcionales que dicho Estado no pudiere controlar, es decir, a un mecanismo que da base para una asistencia financiera ad hoc y meramente puntual.

Tal exclusión de la operatividad del artículo 122.2 TFUE ha sido criticada por algún autor. Así, Adam y Mena Parras señalan que si bien la no aplicación del artículo 143.2 TFUE es poco discutible, dado que dicho precepto viene referido a Estados miembros que no pertenezcan a la eurozona, la exclusión del artículo 122.2 no es tan obvia. Una interpretación hubiera sido posible y, en este sentido, que la ayuda financiera se haya articulado a través de un mecanismo más permanente no evita su condición de ayuda ad hoc, plenamente insertable en las previsiones del artículo 122.2. Además, hacer que la ayuda de la UE dependa de una condicionalidad tan negativa parece poco compatible con el objetivo del correcto funcionamiento de la economía y la unión monetaria recogidos en el artículo 121.4, y en el artículo 136.1 TFUE ${ }^{28}$.

Para el Tribunal, la medida tampoco afecta a la previsión contenida en el artículo 125 TFUE ya que la prohibición que se contiene en el mismo hay que encuadrarla en la idea de responsabilizar a los Estados a mantenerse en la lógica del mercado cuando contraigan deudas, de modo que se sitúen dentro de una sana disciplina presupuestaria, que es, por otra parte, el objetivo de la Unión proyectado en las últimas acciones emprendidas desde la gobernanza europea ${ }^{29}$. De este

27 Hinarejos, A., The Euro Area crisis in constitutional perspective, op. cit., p. 216.

28 Adam, S. y Mena Parras, F.J., «The European Stability Mechanism through the legal meanderings of Union's constitutionalism: Comment on Pringle», European Law Review, vol. 38, n. ${ }^{\circ}$ 6, 2013, pp. 11 y 12.

29 Hinojosa Martínez nos recuerda que la redacción de los artículos 122 y 125 TFUE responde al consenso entre aquellos que querían dotar de todo el rigor a la cláusula de no corresponsabilidad del artículo 125 y aquellos consideraban necesario dejar un resquicio abierto a la posibilidad de que la Unión proporcionase asistencia financiera a un Estado miembro, al menos en circunstancias excepcionales. Vid. HinOjosA 
modo, la cláusula del artículo 125 TFUE, que prohíbe a la Unión y a los Estados miembros otorgar asistencia financiera, pretende tener como efecto alejar la intención del Estado que recibe la ayuda de relajarse, de desatender sus compromisos presupuestarios respecto de la zona euro y de no seguir una política presupuestaria sana y dentro de los márgenes que recoge el propio TFUE. Por ello, la ayuda financiera, en virtud de un mecanismo de estabilidad como el MEDE, solo es compatible con el artículo 125 TFUE si es indispensable para la salvaguardia de la estabilidad financiera de la zona del euro en su conjunto, se supedita a condiciones estrictas y no impide en absoluto que el Estado sigua siendo responsable de sus propios compromisos. Por tanto, el artículo 125 TFUE no prohíbe la concesión de asistencia financiera a un Estado por parte de otros Estados miembros, siempre que el primero continúe siendo responsable, y que las condiciones asociadas a esta ayuda financiera sean apropiadas para estimular al Estado a continuar con una política presupuestaria saludable ${ }^{30}$. La prohibición contenida en el artículo 125 es interpretada teleológicamente en la medida que su fin no es la prohibición de la asistencia financiera entre Estados, sino dicha asistencia cuando pueda promover en el Estado receptor un incumplimiento de sus deberes presupuestarios, de su disciplina presupuestaria ${ }^{31}$. Más, para el TJUE lo previsto en el artículo 122.2 TFUE no supone una excepción a una regla general presuntamente establecida en el artículo 125, como venía interpretándolo la doctrina: «si el artículo 125 TFUE prohibiera toda asistencia financiera por parte de la Unión o los Estados miembros a otro Estado miembro, el artículo 122 TFUE habría debido precisar que constituye una excepción a ese artículo 125 TFUE» ${ }^{32}$. De este modo, el artículo 122.2 TFUE se configura, por tanto, como una «cláusula de crisis» que permite a la Unión proporcionar asistencia financiera a un EM, aunque sometida a condicionalidad. De esa manera, se evita que esta disposición

Martínez, L.M., «La compatibilidad del Mecanismo Europeo de Estabilidad con el Derecho europeo: jurisprudencia para tiempos de crisis», LiÑ́́n Nogueras, D.J. (Dir.), Las crisis políticas y económicas: nuevos escenarios internacionales, Tecnos, Madrid, 2014, p. 14. Puede accederse a dicho trabajo a través del siguiente enlace: http://hdl.handle.net/10481/31649.

30 Serrano Pérez, M., «La Constitución Económica Europea y la gobernanza económica. La Sentencia Pringle: desde la coordinación de la política económica al mecanismo de estabilidad presupuestaria», RFDCP, vol. 43, n. ${ }^{\circ}$ 118, enero-junio 2013, p. 108. Hinojosa Martínez considera acertada la interpretación del art. 125 TFUE en este aspecto, ya que «a la vista de la naturaleza cambiante, y a veces errática, de los mercados financieros, y de la necesidad de salvaguardar la estabilidad financiera de la zona euro en tiempos de crisis» es de «escasa utilidad de intentar consolidar opciones estrictas de política económica mediante su inserción en un texto jurídico. Cuando las necesidades de la realidad superan esa opción económica cristalizada, la norma no tiene más remedio que ser reformada o reinterpretada, puesto que una lectura restrictiva resulta de imposible cumplimiento». Vid. Hinojosa Martínez, L.M., «La compatibilidad del Mecanismo Europeo de Estabilidad con el Derecho europeo: jurisprudencia para tiempos de crisis», op. cit., p. 16. Puede accederse a dicho trabajo a través del siguiente enlace: http://hdl.handle.net/10481/31649.

31 Sobre la interpretación que, en concreto, hace el Tribunal de Justicia del art. 125 TFUE puede verse Craig, P., «Pringle and the nature of legal reasoning», Maastricht Journal of European and Comparative Law, n. ${ }^{\circ} 21,2014$, pp. 218 y 219.

32 Ap. 131 in fine. 
pueda servir para que dicho EM se desvincule de su obligación de mantener una política presupuestaria saneada ${ }^{33}$.

Para el Tribunal, atendiendo a los artículos 4 TUE, apartado 1, y 5 TUE, apartado 2, los Estados miembros cuya moneda es el euro son competentes para celebrar entre ellos un acuerdo por el que se establezca un mecanismo de estabilidad, como el previsto por el artículo 1 de la Decisión 2011/199. Además, la modificación del TFUE no atribuye ninguna competencia nueva a la Unión, no crea ninguna base jurídica con vistas a permitir que la Unión emprenda una acción que no fuera posible antes de la entrada en vigor de la modificación del TFUE. Si los Estados miembros deciden actuar individual o colectivamente en su ámbito de competencia, no hay nada que les impida confiar a la Comisión que garantice la coordinación de dicha acción, correspondiendo entonces a la Comisión decidir si acepta o no tal misión, siempre que lo haga de manera compatible con las obligaciones que le incumben en virtud del ordenamiento comunitario. Por lo tanto, el imperativo fundacional era que los Estados miembros actuaran en su ámbito de competencia, pero siendo posible pedir ayuda a la Comisión, que podría aceptar o no prestarla. Un similar argumento ya fue empleado en el caso de la ayuda a Bangladesh (Parlamento Europeo v Consejo y Comisión, 1993) ${ }^{34}$.

Este último argumento de posible participación de las Instituciones de la Unión en un acuerdo adoptado por los Estados miembros al margen del Derecho de la Unión es el que justifica, además, la propia participación del TJUE en el mecanismo. A este respecto, el artículo 273 TFUE permite que se sometan al Tribunal controversias entre los Estados miembros en ámbitos relacionados con el objeto de los Tratados y es fácil entender que los fines del Mecanismo están directamente relacionados con los fines de la Unión, recogidos en los Tratados ${ }^{35}$.

El Tribunal, por tanto, proclama que los pactos entre Estados miembros son admisibles siempre que se produzcan en una materia que no se encuentre dentro de las competencias exclusivas de la Unión, aún cuando se solicite la cooperación o participación de algunas Instituciones de la Unión, como ocurre en el Mecanismo con la Comisión y el $\mathrm{BCE}^{36}$. Y aquí reside uno de los principales problemas de la doctrina del caso Pringle, al permitir a los Estados miembros pactar fuera del marco legal de la Unión, pero, al mismo tiempo, requerir de la Unión su participación.

33 Hinojosa Martínez, L.M., «La compatibilidad del Mecanismo Europeo de Estabilidad con el Derecho europeo: jurisprudencia para tiempos de crisis», op. cit., p. 14. Puede accederse a dicho trabajo a través del siguiente enlace: http://hdl.handle.net/10481/31649.

34 Casos C-181 y 248/91 [1993] ECR I-3685, par. 20. Vid. CRAIG, P., «Pringle and Use of EU Institutions outside the EU Legal Framework: Foundations, Procedure and Substance», cit., pp. 264 y 268.

35 Hinojosa Martínez, L.M., «La compatibilidad del Mecanismo Europeo de Estabilidad con el Derecho europeo: jurisprudencia para tiempos de crisis», op. cit., p. 10. Puede accederse a dicho trabajo a través del siguiente enlace: http://hdl.handle.net/10481/31649.

36 Adam, S. y Mena Parras, F.J., «The European Stability Mechanism through the legal meanderings of Union's constitutionalism: Comment on Pringle», cit., p. 15. 
En todo caso, también resulta importante recordar que la alternativa del pacto entre Estados miembros y al margen del Derecho de la Unión no sólo respondió a las dificultades legales derivadas de la falta de encaje en los Tratados, sino también a la oposición alemana a la creación de un plan de rescate de conformidad con la legislación de la UE, por cuanto, antes de dicho rescate, se requeriría controlar los presupuestos de los Estados miembros y por el riesgo de que fuera declarado ilegal, no ya por el Tribunal de Justicia, sino por el Tribunal Constitucional Federal alemán. Y tampoco los Estados no miembros de la Zona euro se mostraban a favor de la creación de un fondo de financiación en el marco de la Unión, por el importe que era previsible que hubiera de necesitarse ${ }^{37}$. Todo ello, favoreció acudir a una tendencia «intergubernamental» a la solución de la crisis, es decir, una fórmula fuera del sistema institucional de la Unión ${ }^{38}$.

Tal predominio de la forma intergubernamental, al margen del marco de la Unión, deriva también del necesario fortalecimiento de los ejecutivos nacionales durante la crisis como camino para resolver sus consecuencias corto plazo, sobre todo, por la necesidad de adoptar decisiones políticas en plazos de tiempo extremadamente breves ${ }^{39}$. Se trata, en todo caso, de una fórmula mixta que, pactándose fuera del marco legal de la Unión, exige la participación de las Instituciones de la Unión; en este caso, la Comisión y BCE.

En definitiva, para el Tribunal ni el Mecanismo ni el nuevo artículo 136 TFUE alteran el reparto de competencias previsto en los Tratados y que impide alterar la división competencial en materia económica o monetaria. El nuevo mecanismo, al tratar de «garantizar la estabilidad de la Zona euro en su conjunto», no implica que transfiera competencias sobre el euro. El Mecanismo no es un sistema de coordinación de políticas económicas sino que constituye un mecanismo de financiación, y no altera la competencia exclusiva en materia monetaria de la Unión, y ello, pese a que la asistencia financiera concedida a un Estado miembro, que sea miembro del Mecanismo queda sujeta a una estricta condicionalidad adaptada al instrumento de asistencia elegido, que podrá adoptar la forma de un programa de ajuste macroeconómico ${ }^{40}$. Dicha condicionalidad

37 Hinarejos, A., The Euro Area crisis in constitutional perspective, op. cit., p. 162.

38 PACE, L.F., «The OMT case: Institution Building in the Union and a (failed) nullification crisis in the process of European integration», DANIELE, L. (Ed.), The Democratic Principle and the Economic and Monetary Union, 2016 (en imprenta), p. 8. Puede accederse a dicho trabajo a través del siguiente enlace: http://ssrn. com/author $=812305$.

39 Hinarejos, A., The Euro Area crisis in constitutional perspective, op. cit., pp. 155, 156 y 161.

40 Hinojosa Martínez se muestra crítico con este argumento del Tribunal de Justicia: Desde mi punto de vista, el planteamiento del TJ se muestra algo artificial cuando, para defender que el Tratado MEDE no afecta a las competencias comunitarias de coordinación de las políticas económicas, la sentencia Pringle señala que la condicionalidad prevista «no constituye un instrumento de coordinación de las políticas económicas. En realidad, una cosa es que los memorandos de entendimiento sean compatibles con la coordinación que se lleva a cabo a través del mecanismo comunitario, y otra bien distinta que éstos no constituyan un exigente condicionante coordinado de las políticas económicas nacionales, teniendo en cuenta que obligan a la adopción de programas de ajuste de amplio espectro, que implican una supervisión tremendamente invasiva de las 
no constituye un instrumento de coordinación de las políticas económicas de los Estados miembros, ya que, como establece el artículo 13, apartado 3, párrafo segundo, del Tratado MEDE, deberá ser plenamente compatible con las medidas de coordinación de la política económica previstas en el TFUE. Por otro lado, del apartado 4 del mismo artículo resulta que la Comisión comprobará, antes de firmar el Memorándum de Entendimiento que defina la condicionalidad que acompaña a un apoyo a la estabilidad, que las condiciones impuestas sean plenamente compatibles con las medidas de coordinación de la política económica.

Para el Tribunal resulta relevante que el Mecanismo no asume la garantía de las deudas del Estado miembro beneficiario, ya que, frente a sus acreedores, éste seguirá siendo responsable de sus compromisos financieros. Dicha asistencia conduce a que este último, que sigue siendo responsable de sus compromisos por las deudas existentes frente a sus acreedores, contraiga una nueva deuda frente al Mecanismo.

El caso Pringle ofrece un ejemplo casi paradigmático de diálogo multinivel que se corresponde a una Unión cada vez más compleja en su configuración y procedimientos de solución de conflictos. Este diálogo se lleva a cabo tanto horizontalmente —entre las instituciones de la Unión, como entre las instituciones de la Unión y los Estados miembros- y verticalmente entre el TJUE, por un lado, y los Tribunales Constitucionales y Supremos de los Estados miembros, por otro lado ${ }^{41}$.

Para Aguilar Calahorro, la decisión Pringle es, a primera vista, una expresión de activismo judicial ${ }^{42}$. La decisión muestra a un Tribunal que asume su función de control de las medidas adoptadas en el contexto de la crisis en relación con las previsiones del Derecho de la Unión. Así, el Tribunal afirma que, en virtud del artículo 13, apartado 3, de ese Tratado, el Memorándum de Entendimiento que se negocia con el Estado miembro solicitante de un apoyo a la estabilidad debe ser plenamente compatible con el Derecho de la Unión y en particular con las medidas adoptadas por la Unión en el ámbito de la coordinación de las políticas económicas de los Estados miembros. Por tanto, al menos en parte, las condiciones a las que se somete la concesión de tal apoyo a un Estado miembro serán determinadas por el Derecho de la Unión.

Pese a ello, el Tribunal acaba admitiendo, a través de una interpretación amplia de los Tratados, el encaje comunitario del Mecanismo, y ello, como se ha

políticas presupuestaria y fiscal nacionales. El solapamiento entre estos programas y la coordinación presupuestaria (o los procedimientos de reducción de déficits públicos excesivos) que se desarrolla en el seno de la Unión parece ineludible. Vid. Hinojosa Martínez, L.M., «La compatibilidad del Mecanismo Europeo de Estabilidad con el Derecho europeo: jurisprudencia para tiempos de crisis», op. cit., p. 12. Puede accederse a dicho trabajo a través del siguiente enlace: http://hdl.handle.net/10481/31649.

41 Adam, S. y Mena Parras, F.J., «The European Stability Mechanism through the legal meanderings of Union's constitutionalism: Comment on Pringle», cit., p. 18.

42 Aguilar Calahorro, A., «La posición del Tribunal de Justicia de la Unión Europea frente ...», cit., p. 24. 
señalado por la doctrina, llevado por lo que estaba en juego, la propia integración europea. En opinión de Aguilar Calahorro, Tribunal era muy consciente de que oponerse al nuevo mecanismo financiero mediante una interpretación literal de los Tratados habría dejado a Europa «a la deriva», términos empleados por Hewit ${ }^{43} \mathrm{o}$, como también se ha apuntado, el Tribunal fue consciente de la narrativa de que sin euro no habría ya UE de manera que salvando aquél se garantizaba la pervivencia de ésta ${ }^{44}$.

Sin embargo, siendo ello plausible, el problema no reside tanto en la conformidad del Mecanismo y el concreto Memorándum a los Tratados, en una interpretación muy amplia y generosa de los mismos, sino en que el propio Tribunal viene a limitar de cara al futuro las posibilidades de control jurisdiccional de los mecanismos, tanto a través de la limitación de quiénes estarán legitimados para instar dicho control (las partes contratantes, es decir, los Estados miembros de la zona Euro), como a través de la afirmación de que los derechos fundamentales de la Unión, o lo que viene a ser lo mismo, la Carta no se aplica como parámetro del control de validez de tales Memorándum de entendimiento ${ }^{45}$. Como apunta Goldoni, «this recognition implies the non-applicability of the EU charter of fundamental rights to actions taken by $E U$ institutions outside of the framework of $E U$ law» ${ }^{46}$. El Tribunal ha ignorado deliberadamente las restricciones legales en nombre de la conveniencia política. Las instituciones de la Unión decidieron actuar fuera del ordenamiento jurídico comunitario mediante acuerdos internacionales, consiguiendo de esta manera no quedar sujetos a las restricciones de éste, refugiándose en una zona no jurídica ${ }^{47}$.

Esta última cuestión es abordada por el Tribunal en contestación a la pregunta que le hace la Corte Suprema de la República de Irlanda en relación a que el establecimiento del MEDE fuera del ordenamiento jurídico de la Unión puede tener el efecto de excluirlo del ámbito de aplicación de la Carta, lo que podría suponer una infracción del artículo 47 de la Carta, que garantiza a toda persona una tutela judicial efectiva». Para el TJUE las disposiciones de la Carta tienen eficacia frente a los Estados miembros en la medida que estos apliquen Derecho de la Unión, lo que no concurre en este caso en que los Estados miembros de la Zona euro han acordado acudir a un acuerdo de financiación. El principio general de tutela judicial efectiva no se opone a la celebración entre los Estados miembros

43 Ibidem., p. 24. Sobre Hewit, vid. Hewit, G., Europa a la deriva, Alianza Editorial, Madrid, 2013, pp. 31 y ss.

44 Goldoni, M., «The limits of the legal accountability of the European Central Bank», 7 enero 2016, SSRN, p. 9, https://ssrn.com/abstract $=2712240$.

45 Aguilar Calahorro, A., «La posición del Tribunal de Justicia de la Unión Europea frente ...», cit., pp. 27 y 28.

46 Goldoni, M., «The limits of the legal accountability of the European Central Bank», cit., p. 8, https://ssrn.com/abstract $=2712240$.

47 De WitTe, B., «Euro Crisis Responses and the EU Legal Order: Increased Institutional Variation or Constitutional Mutation?», European Constitutional Law Review, n. ${ }^{\circ} 11,2015$, p. 451. 
cuya moneda es el euro de un acuerdo como el Tratado MEDE ni a su ratificación por éstos.

Para el TJUE los Estados miembros no están comprendidos en el ámbito de aplicación de la Carta al crear el Mecanismo o cuando actúen dentro de su marco. Esto significa que sus acciones no pueden ser revisadas de conformidad con la Carta. Sin embargo, nada dice el Tribunal acerca de la eficacia de la Carta en este ámbito respecto de las Instituciones de la Unión y, particularmente, la Comisión y el Banco Central Europeo, en su condición de firmantes del correspondiente Memorándum ${ }^{48}$. A este respecto, debemos recordar que, de acuerdo con la naturaleza del Mecanismo y su dotación de capital, el cumplimiento de la condicionalidad asociada a los programas de asistencia concedidos será supervisada por la Comisión Europea, en coordinación con el Banco Central Europeo y el FMI. Estas instituciones emitirán informes periódicos sobre el grado de cumplimiento de las condiciones fijadas en el programa de asistencia. La Comisión, por tanto, no sólo participa en la negociación y firma del Memorándum, sino también en a supervisión de su aplicación ${ }^{49}$.

Ante la respuesta dada por el Tribunal, Aguilar Calahorro concluye que el Tribunal ha hecho una inexplicable dejación de funciones en el control del ejercicio del poder supranacional de las instituciones, concediendo plena inmunidad a la Comisión y el BCE en la redacción y supervisión de los Memorándum de entendimiento. Ha omitido cualquier cuestión relativa a la fiscalización de las actuaciones de las instituciones y los Estados en relación con los derechos fundamentales. Así, si bien el Tribunal ha reforzado la efectividad del proceso de integración y el Derecho europeo, ello ha sido al precio de expulsar del terreno dialéctico a los ciudadanos y sus derechos como sujetos privilegiados del Derecho de la Unión. En sus sentencias el lenguaje de los derechos ha terminado por desaparecer para situar en primer plano los conceptos de efecto útil de los Tratados, división competencial en la UE y objetivos de la Unión monetaria ${ }^{50}$. Quedan, pues, debilitados los mecanismos de limitación del poder en garantía de derechos de los ciudadanos, y, singularmente, de los derechos sociales ${ }^{51}$, contribuyéndose a la pérdida de control de la actuación de los gobiernos en el marco global y al soslayo de las propias garantías constitucionales de derechos y libertades por el bien del mercado. La urgencia no reside tanto en el avance en la construcción democrática de Europa, sino en el peligro de sus fundamentos mismos: la propia Comunidad de Derecho ${ }^{52}$.

48 Aguilar Calahorro, A., «La posición del Tribunal de Justicia de la Unión Europea frente ...», cit., pp. 36 y 37 .

49 Urbaneja Cillán, J., «El Mecanismo Europeo de Estabilidad. Análisis a través de la Jurisprudencia comunitaria en el asunto Pringle», cit., p. 140.

50 Aguilar Calahorro, A., «La posición del Tribunal de Justicia de la Unión Europea frente ...», cit., pp. 36 y 37.

51 Hinarejos, A., The Euro Area crisis in constitutional perspective, op. cit., pp. 142 y 143. cit.,. 340 .

52 Aguilar Calahorro, A., «La posición del Tribunal de Justicia de la Unión Europea frente ...», 
Además, de lo manifestado por el Tribunal puede deducirse una doble dimensión en la aplicación de los derechos y la Carta: por un lado, la Carta se aplicará con vigor a situaciones que no son de crisis; por otra, la Carta no se aplicará a las normas derivadas de la respuesta de la Unión a la crisis financiera y económica. Este enfoque no parece mostrarse ni legal ni políticamente sostenible y si bien es comprensible que el Tribunal no haya querido poner en peligro los compromisos políticos necesarios para responder a la crisis, los argumentos que ha utilizado son poco coherentes ${ }^{53}$, más aún, cuando precisamente los derechos han de cobrar un especial importancia en los momentos de crisis cuando más en peligro pueden encontrarse. El fundamento de incluirlos en el ordenamiento comunitario y en los Tratados es, como señala la propia Carta en su Preámbulo, reforzar su protección, lo que cobra mayor virtualidad en aquellos contextos o situaciones en las que pueden estar aún más en peligro.

\section{EL TRIBUNAL AL RESCATE DE LOS DERECHOS: EL CASO LEDRA ADVERTISING}

En el marco del Mecanismo el TJUE ha dictado una nueva Sentencia el 20 de septiembre de 2016, en este caso, referida al Memorándum de Entendimiento con Chipre (Ledra Advertising et al. $v$ European Commission and European Central Bank $)^{54}$.

Como antecedentes, simplemente recordar que el BCE y la Comisión firmaron un Memorándum de Entendimiento de 26 de abril de 2013 con la República de Chipre, bajo la rúbrica de «Reestructuración y resolución del Cyprus Popular Bank y del Bank of Cyprus» ${ }^{55}$. En concreto, se impugnaron los puntos 1.23 a

53 Barnard, C., «The Charter, the Court and the crisis», Paper NO. 18/2013, University of Cambridge Faculty of Law Legal Studies, p. 2. Puede accederse a dicho trabajo a través del siguiente enlace: http:// www.law.cam.ac.uk/ssrn/.

54 Asunto no C-10/2015. En la misma fecha la Gran Sala ha dictado una segunda Sentencia referida también al rescate a la banca chipriota en el que se valoraba, a instancia también de unos inversores, la anulación de la Declaración del Eurogrupo de 25 de marzo de 2013, relativa a la reestructuración de dicho sector bancario en Chipre (caso Mallis v la Comisión y el BCE). La Gran Sala considera, al amparo del art. 137 TFUE, que el Eurogrupo es un foro de discusión, a escala ministerial, de los representantes de los Estados miembros cuya moneda es el euro, y no un órgano decisorio, por lo que una declaración de éste no podía considerarse un acto destinado a producir efectos jurídicos frente a terceros. Además, señala que el hecho de que la Comisión y el BCE participen en las reuniones del Eurogrupo no modifica la naturaleza de sus declaraciones, y no puede llevar a considerar que la Declaración controvertida es resultado de la potestad decisoria de esas instituciones. Así, declara que la Declaración controvertida no incluye ningún elemento que refleje una decisión de la Comisión o del BCE de crear la obligación, para el Estado miembro de que se trata, de aplicar las medidas que contiene dicha Declaración, y no puede considerarse que la adopción por la República de Chipre de la Ley de 22 de marzo de 2013, haya sido impuesta por una supuesta decisión común de la Comisión y del BCE, materializada en la Declaración controvertida.

55 Las razones concretas de la crisis de Chipre son descritas por Sanz Gil y Sanz Romero: Los principales detonantes de la crisis económica de Chipre fue la gran vinculación económica con el país heleno lo que propició 
1.27 del Memorándum que resumidamente disponían que ante la insolvencia de dos de los mayores bancos de Chipre se establecía un plan de resolución y reestructuración, en el que, entre otras operaciones, se llevarían a cabo las siguientes: la cesión de todos los activos y pasivos relacionados con Grecia, que eran adquiridos por el Piraeus Bank, de cuya restructuración se encargarán las autoridades helénicas; y la adquisición por el Bank of Cyprus de los activos chipriotas del Cyprus Popular Bank, salvo los depósitos no garantizados que se mantendrían en la antigua entidad, recapitalizándose aquel. La impugnación de dichos apartados del Memorándum procede de propietarios de los activos que reclamaban de la Comisión y del BCE una indemnización equivalente a la disminución del valor de sus respectivos depósitos y, adicionalmente, la anulación de los citados apartados. La reclamación fue desestimada en su totalidad por el Tribunal General, por considerarlos en parte inadmisibles y en parte manifiestamente desprovistos de fundamento jurídico alguno.

El Tribunal General consideró, por un lado, que la Comisión y el BCE no habían promovido la adopción del Memorándum de Entendimiento de 26 de abril de 2013 y, en consecuencia, se declaró incompetente para pronunciarse sobre los recursos de indemnización en la medida en que se basaban en la ilegalidad de los puntos controvertidos, y, por el otro, que los recurrentes no habían demostrado que el daño que alegan haber sufrido tuviera su causa en el incumplimiento por parte de la Comisión de una supuesta obligación de garantizar la compatibilidad del Memorándum de Entendimiento de 26 de abril de 2013 con el Derecho de la Unión. El citado Memorándum fue adoptado conjuntamente por el Mecanismo y por la República de Chipre, limitándose la Comisión a firmarlo en nombre del Mecanismo. Y a este respecto, el Tribunal General, con mención de la doctrina contenida en el caso Pringle señala que, aun cuando el Tratado MEDE encomienda a la Comisión y al BCE ciertas tareas ligadas a la ejecución de los objetivos de dicho Tratado, por un lado, las funciones atribuidas a la Comisión y al BCE en el marco del Tratado MEDE no comprenden ninguna potestad decisoria propia y, por otro lado, las actividades ejercidas por esas dos instituciones en el marco de dicho Tratado sólo vinculan al Mecanismo. A este respecto, recuerda el Tribunal General que, tal como resulta de la declaración del Eurogrupo de 27 de junio de 2012, se encargó a la Comisión y al BCE que negociaran con las autoridades chipriotas un programa de ajuste macroeconómico que debía concretarse en un memorándum de entendimiento. Mediante su participación en las negociaciones con las autoridades chipriotas, la aportación de sus conocimientos técnicos y el asesoramiento y la orientación ofrecidos, la Comisión y el BCE actuaron dentro de

un contagio a la economía chipriota debido a los problemas griegos. Por otro lado, Chipre tenía un sector financiero excesivamente grande para el tamaño del propio país, que había sido alimentado principalmente por capital extranjero. Esto unido a que durante los años previos a la crisis Chipre había experimentado una expansión muy grande del mercado inmobiliario. Vid. SANZ GiL, J.J. y SANZ Romero, A., «Aplicación del Mecanismo Europeo de Estabilidad en el sistema financiero chipriota», RUE, n. ${ }^{\circ}$ 21, diciembre 2014, p. 117. 
los límites de las competencias que les confiere el artículo 13, apartado 3, del Tratado MEDE. Por consiguiente, la participación de la Comisión y el BCE, con arreglo a lo previsto por dicho artículo, en el procedimiento que estaba destinado a la firma del Memorándum de Entendimiento de 26 de abril de 2013 no permite concluir que este acto les fuera imputable.

La opinión anterior será compartida no sólo por la Comisión y el BCE, sino también por el el Abogado General en sus conclusiones, para quien la circunstancia de que una o varias instituciones de la Unión puedan desempeñar ciertas funciones en el marco del MEDE no altera la naturaleza de los actos del MEDE, que no pertenecen al ordenamiento jurídico de la Unión.

Pues bien, a diferencia de la posición adoptada por el Tribunal General, la Gran Sala viene a admitir a trámite los recursos de casación, no admitiendo, además, la petición de inadmisibilidad alegada por la Comisión y el BCE. Estos alegaron ante la Gran Sala que los recurrentes se limitaban, en esencia, a reproducir los motivos y las alegaciones previamente formuladas ante el Tribunal General y que impugnaban las apreciaciones de los elementos de hecho efectuadas por el Tribunal General sobre las distintas pruebas aportadas. Sin embargo, a este respecto, la Gran Sala, pese a reconocer que los recursos no cumplen los requisitos de motivación establecidos en la regulación del recurso de casación, al limitarse a repetir o a reproducir literalmente los motivos y las alegaciones formulados ante el Tribunal General, incluidos los basados en hechos expresamente desestimados por ese órgano jurisdiccional, siendo el recurso una demanda destinada a obtener un mero reexamen de la presentada ante el Tribunal General, lo cual excede de la competencia del TJUE, admite entrar a valorar los mismos. Tal decisión la fundamenta en su doctrina jurisprudencial que permite volver a discutir en el marco de un recurso de casación las cuestiones de Derecho examinadas en primera instancia (vid., en especial, la Sentencia de 4 de septiembre de 2014, España/Comisión, C-192/13 P, EU:C:2014:2156, apartado 45 y jurisprudencia citada en la misma). Y si bien es cierto, en palabras de la Gran sala, que la estructura argumental seguida por las partes en sus recursos de casación carece de rigor, no obstante, se ha de señalar que en ellos se identifican los extremos de los motivos impugnados de los autos recurridos y los fundamentos jurídicos que permiten al TJUE efectuar el control de legalidad conforme a Derecho.

Así pues, los antecedentes reseñados permiten percibir cómo la Gran Sala entra a valorar un recurso que, por defectos formales, podría haber fácilmente inadmitido a trámite, lo que ya indica una determinada voluntad en el propio Tribunal.

Una vez salvada dicha cuestión, la Gran Sala entra a valorar los argumentos de fondo de los recurrentes para fundamentar su pretensión de reparación de la disminución del valor de sus activos que son, sustancialmente, imputar a la Comisión un incumplimiento de su deber de velar por la compatibilidad con el Derecho de la Unión de los Memorandos de Entendimiento concluidos por el Mecanismo (inacción de la Comisión), invocando la doctrina consagrada en el 
caso Pringle. Según los recurrentes, el propio Tribunal de Justicia había señalado que la condicionalidad asociada al instrumento de asistencia financiera debe ser conforme al Derecho de la Unión. A este respecto, los recurrentes invocan la Carta, al considerar que la aplicación de una medida de saneamiento interno como la que figura en los puntos controvertidos constituye una vulneración manifiesta del derecho de propiedad, consagrado en su artículo 17, apartado 1, de la Carta y el artículo 1 del Protocolo adicional n. ${ }^{\circ} 1$ del Convenio Europeo de Derechos Humanos.

Tal argumento es admitido por la Gran Sala que, con apoyo en la doctrina consagrada en el caso Pringle, considera que las tareas confiadas a la Comisión y al BCE en el marco del Tratado MEDE no desvirtúan las atribuciones que los Tratados UE y FUE confieren a esas instituciones y, en particular, en lo que atañe a la Comisión, del artículo 17 TUE, apartado 1, resulta que ésta «promoverá el interés general de la Unión» y «supervisará la aplicación del Derecho de la Unión». Asimismo, las tareas atribuidas a la Comisión por el Tratado MEDE le imponen, como prevé el artículo 13, apartados 3 y 4, de éste, la obligación de velar por la compatibilidad con el Derecho de la Unión de los memorandos de entendimiento concluidos por el MEDE.

La Gran Sala viene a compartir parcialmente el criterio del Tribunal General y reitera que el Memorándum de Entendimiento no puede ser objeto de recurso de anulación, al quedar tales actos fuera del ámbito de aplicación del Derecho de la Unión. Para la Gran Sala, la implicación de la Comisión y del BCE no cambia tal conclusión y no es suficiente para atribuirles la autoría de estos actos a efectos de control jurisdiccional. Sin embargo, a continuación, añade que, aunque no sean sus autores, la participación de la Comisión y del BCE en la adopción de un Memorando de Entendimiento puede ser ilegal y, por lo tanto, generar responsabilidad de las Instituciones de la Unión, debiendo recordarse que la Comisión, singularmente, conserva su papel de guardiana de los Tratados, aún cuando actúe en el ámbito del Mecanismo. Tal función de guardiana le obliga a abstenerse de firmar un Memorándum respecto al que albergue dudas sobre su compatibilidad con el Derecho de la Unión.

De todo ello resulta que, para la Gran Sala, el Tribunal General incurrió en error de Derecho en cuanto se refiere a la interpretación y la aplicación del artículo 268 TFUE y del artículo 340 TFUE, apartados segundo y tercero, al considerar que no era competente para examinar un recurso de indemnización fundado en la ilegalidad de los puntos controvertidos basándose en la mera constatación de que su adopción no era formalmente imputable ni a la Comisión ni al BCE, por lo que procede estimar los recursos de casación y anular los autos recurridos.

Por lo que se refiere al fondo de las reclamaciones, la Gran Sala invoca la competencia prevista en el artículo 61, párrafo primero, del Estatuto del TJUE, que prevé que en caso de anulación de la resolución del Tribunal General, el Tribunal de Justicia podrá resolver definitivamente el litigio, cuando su estado así lo permita, lo que concurre para la Gran Sala en este caso, ya que en virtud del 
artículo 268 TFUE y del artículo 340 TFUE, párrafos segundo y tercero, el Tribunal de Justicia es competente para conocer de la pretensión de las recurrentes relativa a la indemnización por el daño que alegan haber sufrido como consecuencia, por una parte, de la inclusión por la Comisión y el BCE de los puntos controvertidos en el Memorándum de Entendimiento de 26 de abril de 2013 y, por otra parte, del incumplimiento de la Comisión de su obligación de velar, en el marco de la adopción de dicho Memorándum de Entendimiento, por que éste fuera conforme al Derecho de la Unión.

Sin embargo, la Gran Sala acaba desestimando el fondo de la reclamación al no admitir que la Comisión hubiera incurrido en una violación del derecho de propiedad de las recurrentes garantizado por el artículo 17, apartado 1, de la Carta. Tal falta de violación impide considerar que concurra, ni siquiera, el primero de los requisitos exigidos para que surja la responsabilidad extracontractual de la Unión, como es el del carácter ilícito de la actuación imputada a la institución de la Unión, que junto a la realidad del daño y la existencia de una relación de causalidad entre la actuación de la institución y el perjuicio invocado, conformen los tres requisitos de enjuiciamiento de dicha responsabilidad.

Así, la Gran Sala recuerda que, en relación al requisito del carácter ilícito de la actuación, es preciso acreditar la existencia de una violación suficientemente grave o suficientemente caracterizada en los términos literales usados por el Tribunal (sufficiently serious breach) ${ }^{56}$, no bastando una mera infracción, de una norma jurídica que tenga por objeto conferir derechos a los particulares, en este caso, como ya hemos mencionado, sería el artículo 17 de la Carta que consagra el derecho a la propiedad privada.

56 Recuérdese que dicho concepto es introducido en el seminal case, Brasserie du Pêcheur v Germany and R (Factortame) v SS for Transport (No 3), (1996) C-46/93 and C-48/93, ECR I-1029. El Tribunal de Justicia establece los siguientes criterios para determinar cuando estamos en presencia de una violación suficientemente grave o caracterizada de las normas: a) El criterio decisivo para considerar que una violación del Derecho comunitario es suficientemente caracterizada es el de la inobservancia manifiesta y grave, por parte tanto de un Estado miembro como de una Institución comunitaria, de los límites impuestos a su facultad de apreciación (ap. 55). b) Entre los elementos que el órgano jurisdiccional competente puede tener que considerar, debe señalarse el grado de claridad y de precisión de la norma vulnerada, la amplitud del margen de apreciación que la norma infringida deja a las autoridades nacionales o comunitarias, el carácter intencional o involuntario de la infracción cometida o del perjuicio causado, el carácter excusable o inexcusable de un eventual error de Derecho, la circunstancia de que las actitudes adoptadas por una Institución comunitaria hayan podido contribuir a la omisión, la adopción o al mantenimiento de medidas o de prácticas nacionales contrarias al Derecho comunitario (ap. 56) c) En cualquier caso, una violación del Derecho comunitario es manifiestamente caracterizada cuando ha perdurado a pesar de haberse dictado una sentencia en la que se declara la existencia del incumplimiento reprochado, de una sentencia prejudicial o de una jurisprudencia reiterada del Tribunal de Justicia en la materia, de las que resulte el carácter de infracción del comportamiento controvertido (ap. 57). Esta doctrina se completa posteriormente en Laboratoires pharmaceutiques Bergaderm SA and Jean-Jacques Goupil v Commission of the European Communities, 2000, en la que se reitera que la determinación de cuando la infracción es grave o caracterizada depende del margen de discrecionalidad que ostente la Institución a la hora de aplicar la norma comunitaria presuntamente causante del daño al particular. Sobre dicho concepto, vid. VAn Dam, C., European Tort Law, Oxford University Press, Oxford 2014, pp. 559 a 566. 
Pues bien, la Gran Sala considera que la Comisión no incurrió en una violación suficientemente grave del derecho de propiedad de las recurrentes, en el sentido del artículo 17, apartado 1, de la Carta, en el marco de la adopción del Memorándum de Entendimiento de 26 de abril de 2013, ya que conforme tiene consagrada la jurisprudencia comunitaria (Sentencias de 16 de noviembre de 2011, Bank Melli Iran/Consejo, C-548/09 P, EU:C:2011:735, apartado 113, y de 12 de mayo de 2016, Bank of Industry and Mine/Consejo, C-358/15 P, EU:C:2016:338 apartado 55), tal derecho no constituye una prerrogativa absoluta, pudiendo ser su ejercicio objeto de restricciones justificadas por objetivos de interés general perseguidos por la Unión.

La Gran Sala estima que concurren tales restricciones justificadas en la medida que la adopción de un memorándum de entendimiento como el resultante de las negociaciones entre las autoridades chipriotas y, en particular, la Comisión, responde a un objetivo de interés general perseguido por la Unión, que es garantizar la estabilidad del sistema bancario de la zona del euro en su conjunto. Y así recuerda que los servicios financieros desempeñan un papel fundamental en la economía de la Unión, siendo los bancos y las entidades de crédito son una fuente esencial de financiación para las empresas que operan en los diferentes mercados. Además, al estar los bancos a menudo interconectados, ejerciendo muchos de ellos sus actividades en el plano internacional, es lógico admitir que las dificultades de uno o de varios bancos pueden propagarse rápidamente a los otros, en el Estado miembro interesado o bien en otros Estados miembros, lo que puede producir efectos en cadena negativos en otros sectores de la economía.

Siendo el objetivo del Memorándum garantizar la estabilidad del sistema bancario en la zona del euro y del riesgo inminente de pérdidas financieras al que habrían estado expuestos los depositantes de los dos bancos afectados en caso de quiebra de estos últimos, tales medidas no constituyen una intervención desmesurada e intolerable que lesiona la propia esencia del derecho de propiedad de las recurrentes. Por consiguiente, no pueden ser consideradas como restricciones injustificadas del derecho de propiedad.

De lo dispuesto por la Gran Sala resulta que las decisiones adoptadas en el marco del Mecanismo pueden ser impugnadas judicialmente al amparo del ejercicio de una acción de responsabilidad extracontractual por incumplimiento de sus deberes por parte de alguna de las Instituciones de la Unión, pero no mediante el ejercicio de la acción de nulidad. A este respecto, debemos recordar que si bien el plazo de ejercicio de la primera es mucho más amplio que la segunda (cinco años frente a dos meses), la posibilidad de obtener un pronunciamiento positivo es más difícil ya que se exige en las acciones de responsabilidad extracontractual una actuación manifiestamente grave y no una mera infracción del ordenamiento jurídico.

Como puede comprobarse, dicha decisión de la Gran Sala puede considerarse como una confirmación no sólo del rescate a la República de Chipre, sino, más 
allá, de la propia Carta que si bien en el caso Pringle parece que no ha de servir como regla de enjuiciamiento de la función de la Comisión y el BCE en el ámbito de la adopción de los Memorándums al amparo del Mecanismo de Estabilidad, aquí parece que ha operado plenamente, aún cuando la decisión final fuera desestimatoria por estar justificado el límite al derecho de propiedad de los recurrentes. De la decisión de la Gran Sala puede extraerse la conclusión de que sobre las instituciones de la Unión, en particular, la Comisión y el BCE, recae el deber de velar, en el marco de la firma de los Memorándums de Entendimiento en el marco del Mecanismo, por el cumplimiento del Derecho de la Unión y, singularmente, por el de los derechos consagrados en la Carta, debiendo abstenerse de firmarlos si se vulneran.

Los medios de comunicación que se han hecho eco de dicha decisión han señalado que pese a que la decisión tenga cierto carácter simbólico, viene a reconocer la relevancia de los derechos fundamentales y los derechos sociales de los ciudadanos de la Unión incluso en tiempos de acuerdos de rescate y de políticas de estricta austeridad. Incluso, algún miembro del Parlamento Europeo como el verde Sven Geigold ha afirmado que la decisión «is a landmark for the protection of fundamental rights. The judges opened the door to damage claims against austerity measures in countries such as Greece, Portugal, Ireland and Cyprus, where individual and social rights are affected ${ }^{57}$.

Así pues, el Tribunal de Justicia parece volver a la senda de los derechos lo que nos permite afirmar que se ha recuperado el principio de democracia de la Unión a través de la proclamación de la eficacia de los derechos consagrados en la Carta como parámetro de enjuiciamiento de los acuerdos que se adopten al amparo del Mecanismo. Ya no sólo cuenta el efecto práctico u utilidad económica del rescate, sino también los derechos de los ciudadanos de la Unión.

Cierto es, sin embargo, que la exclusión de la Carta del enjuiciamiento de la aplicación de medidas económicas como las previstas en el Mecanismo vino explícitamente circunscrita a los Estados miembros participantes en el rescate y no a las Instituciones de la UE, por lo que tampoco podemos considerar el caso Lendra Advertising como un cambio de doctrina respecto de Pringle, pero sí, al menos, un límite explícito a dicha huida del marco de eficacia de la Carta.

$$
* * *
$$

TITLE: The European Court of Justice to the rescue of rights in the context of the stability measures derived from the economic crisis.

ABstract: The economic crisis, which has affected the Member States of the Union in this decade, has shown that the mechanisms of economic co-operation and coordination between the Union and the Member

57 Vid. blog Keep Talking Greece, en su edición del 21 de septiembre de 2016, http://www.keeptalkinggreece.com. 19/12/2016. 
States, far beyond the single monetary policies, have proved insufficient to overcome an economic and political instability situation. Therefore, the Union institutions and Member States chose to extend their economic powers by creating new instruments, notably the European Stability Mechanism. This has been subject to scrutiny by the Court of Justice in the Pringle case, where the doctrine considered that the Court had very wrongly excluded the Charter as a legal way to guarantee fundamental rights of citizens of the Union in the context of the economic rescues. However, this path which gives prominence to the Charter seems to have been recovered by the Court in the recent Ledra Advertising case.

RESUMEN: La crisis económica que ha afectado a los Estados miembros de la Unión en esta década ha demostrado que los mecanismos de cooperación y coordinación económica entre la Unión y los Estados, más allá de las políticas únicas monetarias, se han mostrado harto insuficientes de cara a superar la situación de inestabilidad económica y política. Por ello, las instituciones de la Unión optaron por extender sus competencias económicas, creando nuevos instrumentos, entre los que destaca el Mecanismo Europeo de Estabilidad. Este se ha visto sujeto al escrutinio del Tribunal de Justicia en el caso Pringle, donde la doctrina consideró que de manera muy desacertada el Tribunal habia excluido a la Carta como parámetro de enjuiciamiento del respeto por parte de los rescates de los derechos fundamentales de los ciudadanos de la Unión. Sin embargo, esta senda que otorga el protagonismo a la Carta parece haberse recuperado por el Tribunal en el reciente caso Ledra Advertising.

KEY WORDS: European Court of Justice, Charter of Fundamental Rights of the European Union, European Stability Mechanism, European Central Bank, European Commission, extra-contractual liability, right of property, intergovernmental relations.

Palabras Clave: Tribunal de Justicia, Carta de Derechos de la UE, Mecanismo Europeo de Estabilidad, Banco Central Europeo, Comisión Europea, responsabilidad extracontractual, derecho de propiedad, relaciones intergubernamentales.

FECHA DE RECEPCIÓN: 26.12.2016

FECHA DE ACEPTACIÓN: 01.02.2017 